PROJETOS URBANOS E FORMAÇÃo dA CIDADE OITOCENTISTA

\title{
Socialismo e progresso no Rio de Janeiro do século XIX
}

FRIDMAN, Fania

\begin{abstract}
Resumo
O artigo é uma leitura do Rio de Janeiro no século XIX, quando propostas de harmonia, progresso, abolição da escravatura e preceitos higienistas para a moradia e a cidade foram trazidas por homens e livros para o país. São apresentados alguns resultados de uma pesquisa em curso voltada para as ressonâncias do ideário socialista romântico nos projetos urbanísticos, implementados ou não, para a capital imperial. As principais fontes de consulta foram a bibliografia especializada e os periódicos publicados na cidade.
\end{abstract}

Palavras-chave: Rio de Janeiro. Socialismo Romântico. Urbanismo. Planejamento Urbano e Regional.

\begin{abstract}
:
This paper is a reading of nineteenth-century Rio de Janeiro, when the arrival of individuals and books in Brazil brought with it proposals regarding social harmony, progress, the abolition of slavery, and hygienic innovations for housing and for the city as a whole. The paper presents results of an ongoing research project focused on the resonance of romantic socialist ideology in urbanistic projects (whether implemented or not) within Brazil's imperial capital. The main sources of research are contemporary specialized literature and local periodicals.
\end{abstract}

Keywords: Rio de Janeiro. Romantic Socialism. Urbanism. Urban and Regional Planning. 


\section{O socialismo romântico e seus projetos}

Com os Descobrimentos, a América tornou-se o lugar da esperança e da utopia, onde o homem poderia construir uma sociedade melhor (ABRAMSON, 1999). Ainda que as sociedades criadas pelos colonizadores portugueses, espanhóis, franceses, holandeses e ingleses tivessem como base de sustentação a violência da escravatura e da submissão dos nativos, no século XIX permaneceria como a terra onde tudo seria possível. Para este continente vieram muitos socialistas românticos ${ }^{1}$ (ou utópicos, para Marx e Engels, ou pragmáticos, segundo Lima Sobrinho) como Saint Simon, Victor Considérant, Michel Chevalier, Jean-Baptiste Eugène Tandonnet, Louis Léger Vauthier, Benoit Jules Mure e Antoine A. Hubert, entre tantos outros, e chegaram livros e periódicos que fomentaram experimentações de ideais progressistas, cristãos e revolucionários. Para Hobsbawm (1994), estes ideários foram herança da "dupla revolução" francesa e industrial da segunda metade do século XVIII, que instaurou o triunfo da indústria capitalista e do Estado moderno na Europa, trazendo o progresso técnico, a nova economia, a nova sociedade, os dramas para o povo e as alternativas para um mundo melhor.

Se desde as primeiras décadas do Oitocentos as cidades industriais passaram a ser responsabilizadas pelas graves dificuldades sociais ou elas mesmas encaradas como problemas, para resolvê-los e transformar a sociedade de modo pacífico e radical, Saint Simon dizia ser necessária uma base cristã na organização científica da indústria e dos homens. Quanto à disposição urbana, o socialismo sansimoniano tinha como um de seus traços distintivos a prioridade às vias de comunicação, que trariam a paz e a felicidade para a humanidade.

Charles Fourier, em sua crítica ao capitalismo, apontava a cidade como epicentro. Dizia ser preciso extinguir as grandes capitais (dada a impossibilidade de reformá-las) e organizar falanstérios que abrigariam 1.600 pessoas. Neles haveria um núcleo central, as praças tomariam a oitava parte do assentamento, as ruas teriam dezoito metros de largura, a altura das construções com a mesma medida e as indústrias ficariam nos subúrbios rodeados por avenidas. Acrescente-se ainda que o principal órgão do movimento fourierista, o jornal La Démocratie Pacifique, teria se integrado ao debate urbanístico de seu tempo (MORET, 2001). Para superar a precária condição das populações urbanas,

1. Utilizo a expressão "socialismo romântico" tal como o faz Lowy (2008) seguindo a proposição de Georg Lukács. inclusive lutando pela abolição da escravatura, seu discípulo dileto Victor Considérant pregava um sistema que realizaria o cristianismo nas cidades através da higiene, do conforto e da estética com a retilinearidade e ampliação da largura das ruas e a eliminação do lixo, dos cafés e das casas de jogos.

Michel Perreymond (provavelmente um pseudônimo) publicou nove estudos na Revue Générale de l'Architecture et des Travaux Publics. Tal como Fourier, discordava das intervenções pontuais. Para resolver os problemas sanitários e da circulação de Paris, sugeria um "plano de conjunto" baseado na circulação "na" e "a partir" da cidade com o alargamento e abertura de vias e a melhoria dos meios de transporte. Estas medidas proporcionariam uma cidade concêntrica com hierarquização de seu espaço e o progresso da hinterlândia, aliando o desenvolvimento econômico à técnica. Seus estudos versavam ainda sobre o núcleo central, extinguindo suas partes decadentes e atribuindo-lhe funções administrativas, culturais, religiosas, comerciais e de moradia. Propunha ainda o abastecimento d'água, a conexão entre as edificações e novas praças, demandas reclamadas pela população, pela imprensa e pelos conselheiros municipais.

Os problemas urbanos também se constituíram em tema dos filantropos e católicos. Na década de 1840, o médico francês Louis-René Villermé realizou um inquérito sobre a qualidade de vida dos operários, incluindo a moradia, as doenças e a organização social. Na mesma ocasião, a Ordem de São Vicente de Paula levantou as condições de higiene dos alojamentos dos trabalhadores em Lille, e a Société d'Economie Charitable publicou pesquisas sobre o estado sanitário dos bairros pobres, utilizadas pelo socialista revolucionário Louis Auguste Blanqui em suas denúncias do capitalismo.

\section{Os socialismos românticos brasileiros através de periódicos e de um livro}

O primeiro periódico no Brasil a explicitar o termo socialismo teria sido $O$ Globo, em cuja edição inicial o definia como uma "ciência social" de ordenação do trabalho. Ao socialismo acompanhava o plano, binômio fundamental que iremos verificar em vários exemplos adiante. Neste jornal encontram-se os fundamentos da teoria de Fourier "ainda muito estranha no Brasil" (p. 3) e a recomendação de um "plano de organização para as vilas que [os novos habitantes] devem povoar" (13 out. 1844, p. 2) antes da implementação da política de imigração. ${ }^{2}$ 
Nossas cidades insalubres, nossas aldeias, nossas vilas serão substituídas pelas salubres e suntuosas moradas discutidas pelo gênio de Fourier. Este palácio fornecerá todo o necessário e ainda o ar, a água pura, a luz, o calor, conforme o gosto de cada um. [...]. Todo o trabalho executado em comum nas salas de reunião, nas oficinas ou nos risonhos campos do falanstério se tornará um prazer e uma festa. [...] A idade do ouro vai renascer. A harmonia substituirá a discórdia. A nova Jerusalém descerá sobre a terra, Deus habitará entre nós (p. 3, 4).

Na mesma época tem-se a presença do médico francês Benoit Jules Mure. Após a experiência falansteriana em Santa Catarina, deslocou-se em 1842 para o Rio de Janeiro, onde abriu o primeiro dispensário homeopático em conjunto com Manuel Gaspar de Siqueira Rego, João Vicente Martins e Edmond Tiberghien. Declarados "discípulos veneradores de Fourier", publicaram O Socialista da Província do Rio de Janeiro, que saía a cada três dias a partir de $1^{\circ}$ de agosto de 1845. No primeiro número o socialismo foi interpretado como "introdução de novidade no progresso universal [...] quer na parte moral, quer na material [...] seu fim é ensinar aos homens a se amarem uns aos outros" (apud RODRIGUES, 1996, p. 3), conservando o que houvesse de bom e melhorando o insuficiente. A gazeta manifestava-se a favor do fim da escravidão, da demarcação das terras indígenas, da conservação (com reformas) da monarquia constitucional para a estabilidade política, e da homeopatia em favor dos despossuídos. O também francês Jean-Baptiste Eugène Tandonnet, outro discípulo de Fourier, chegou ao Rio de Janeiro em 1845 vindo de Montevidéu e, com um grupo de falansterianos franceses, fundou a Revue Socialiste e tornou-se colaborador de $\mathrm{O}$ Socialista da Província do Rio de Janeiro.

A Nova Minerva, editada entre dezembro de 1845 e julho de 1846, apoiava os benefícios da homeopatia e, por considerar dever do governo

\footnotetext{
2. No entanto também dizia ter sido a Revolução Francesa "um acontecimento desgraçado que retardou os progressos reais". Lembre-se que no começo da década de 1840 desembarcaram em Recife engenheiros franceses contratados pelo governo da província. Um deles, Louis Léger Vauthier, era um politécnico fourierista que fez amizade com o fundador da revista $\mathrm{O}$ Progresso, de grande repercussão ao divulgar a necessidade de expropriação de terras; do imposto territorial sobre áreas não exploradas e as heranças e rendas superiores a 200 mil réis anuais; da "celeridade no transporte"; de incentivo a pequenos e médios proprietários rurais; da libertação dos escravos; da criação de um Banco Popular, da reorganização espacial com novas circunscrições territoriais e de Conselhos Provinciais para verificação das contas dos órgãos públicos.
}

socorrer "o homem laborioso", propôs o estabelecimento de uma junta de caridade e de beneficência em cada bairro que
[...] concederia, segundo as circunstâncias, às pessoas inferiores e aos operários que se achassem em miséria por moléstia ou causas independentes deles, socorros resultantes ou de subscrições voluntárias ou de um livre imposto realizado, por exemplo, por um tanto sobre o valor dos aluguéis, fundos que ficariam à disposição das juntas de beneficência. (Jul. 1846, p. 106).

O Hahnemannista defendia a homeopatia e os preceitos higienistas - banhos, ar puro ("longe dos centros das cidades, das cloacas e dos pântanos"), casas construídas acima do nível do solo, expostas ao vento leste e com aberturas para entrada da luz "em rua vasta ou um quarteirão pouco populoso" (17 set. 1846, p. 1, 2). A higiene também era assunto da bissemanal $A$ Marmota na Corte, em torno da qual se reuniam representantes do romantismo pedindo urgentes providências contra o "despejo noturno [...] na verdade um tal uso desacredita a nobreza desta côrte que aliás se acha em tantos apuros, quer dizer, civilizada e desenvolvida até certo ponto" (2 out. 1849, p.1).

Com ironia, o abolicionista Correio Mercantil, que circulou entre 1848 e 1868 com crônicas de Machado de Assis e de José de Alencar, anunciava seu prognóstico para o ano que se iniciava:

\footnotetext{
Os moradores de São Cristovão, Benfica e Praia Pequena terão água a fartar, em cumprimento das promessas do diretor das obras públicas. Os capoeiras deixarão de infestar as praças e ruas da cidade, porque os cativos serão castigados com açoites segundo as ordens da polícia, e os libertos serão recrutados para o exército ou marinha, onde poderão gingar à sua vontade. (2 jan. 1848, p.1).
}

A revista $O$ Guanabara, dirigida por três literatos consagrados, Manuel de Araújo Porto Alegre, 3 Joaquim Manuel de Macedo e Antônio Gonçalves Dias, expunha sua posição em 1849: "[...] devemos concentrar todas as nossas forças para o desenvolvimento moral e intelectual, única base de um seguro e permanente progresso" (apud MATTOS, 2007, p. 22).

3. Porto Alegre foi aluno de Debret no Rio de Janeiro, com quem seguiu para Paris em 1831, onde entrou em contato com o movimento romântico. 
O hebdomadário Courrier du Brésil, que saiu aos domingos cariocas entre 1854 e 1862 e cujo editor foi o socialista Antoine Hubert, recebia contribuições de exilados e de entusiastas do movimento francês de 1848. E aquele que talvez possa ser considerado o primeiro jornal operário, - Eco da Imprensa, foi editado a partir de 1856, pela Associação Tipográfica Fluminense. Durante seu movimento grevista em 1858 foi publicado o Jornal dos Tipógrafos, onde se divulgavam ideais socialistas: "Já é tempo de acabarem as opressões de toda a casta; já é tempo de se guerrear por todos os meios legais toda a exploração do homem pelo mesmo homem" (apud RODRIGUES, 1996, 4).

O papel de órgão de denúncia desempenhado pela imprensa pode ser acompanhado no semanário O Compilador, sobre a situação sanitária do Rio de Janeiro que "não é infelizmente qual seria de desejar" (17 maio 1852, p. 2), dada a insuficiência de meios para combater a febre amarela.

Como democratas e revolucionários a soberania nacional é o nosso dogma, a liberdade o nosso princípio. (24 maio 1852, p.1).

A nós que aqui estamos não nos espanta tanto o mapa [oficial da mortalidade], o que nos espanta é o abandono imperdoável em que se acha a cidade, a mais sã até há poucos anos passados. (7 jun. 1852, p.1).

A constituição diz que a lei é igual para todos [...] e o povo vê, sente que o mais escandaloso patronato rouba mil vezes o direito, a quem o tem; e que a proteção da lei é somente privilégio do rico, assim como castigo cai unicamente sobre a cabeça do pobre. (28 nov. 1852, p. 3).

No semanário $A$ Abelha encontra-se um comentário elogioso ao livro Curso de Economia Política, de autoria do sansimonista Michel Chevalier (30/4, p.7). E apoiando os preceitos higienistas reconhecia como

\footnotetext{
[...] de absoluta necessidade que as autoridades sanitárias e administrativas examinem os estabelecimentos e processos industriais, [...] [se] neles são guardadas as regras e preceitos da higiene pública e polícia sanitária [...] e que uma lei regule a duração do trabalho nas oficinas. (16 fev. 1856, p. 4).
}

O general José Inácio de Abreu e Lima, declarando-se sansimonista, fourierista, comunista, abolicionista, antirracista, defensor da propriedade privada limitada pelos interesses sociais e monarquista (por acreditar que a monarquia seria o único meio de garantir a unidade do Brasil), escreveu o livro O Socialismo (1855).

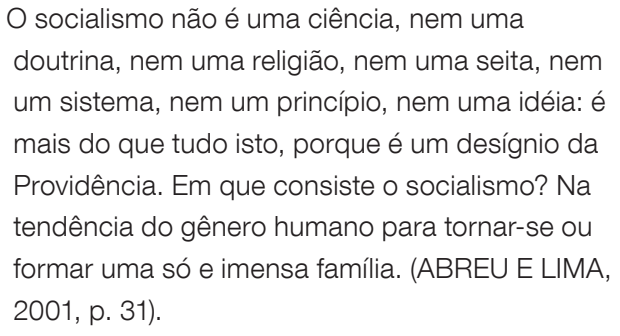

Inúmeras publicações circularam, mas fiquemos apenas com o revolucionário $O$ Socialista que, em sua primeira edição (20 jul. 1878), ao considerar a "monarquia morta pela ideia republicana", tinha como princípio "alertar as classes responsáveis pelo nosso miserando estado social e elevar o nível moral do povo" (p.1). E proclamava: "A doutrina socialista não exclui a relatividade da propriedade, nega absoluto direito a ela" (3 ago. 1878, p.1).

\section{Projetos socialistas para o Rio de Janeiro?}

Relevantes e pontuais intervenções ocorreram após a chegada da Missão Francesa em 1816, especialmente para a área de expansão, a Cidade Nova, onde se fixou o centro de poder do império português. Os anos que se seguiram marcaram o "urbanismo imperial" (FRIDMAN, 2009), coletânea de soluções que procuraram demonstrar a nova condição de corte e de capital de um país. A contar da terceira década do século XIX, o Rio de Janeiro dispunha de posturas relativas à salubridade, à demarcação de um canal e de caminhos, ao alinhamento das ruas e ao desenho de quadrados perfeitos para praças e largos (MENDONÇA, 1936).

Pode-se afirmar que o Relatório do diretor de Obras Públicas, o engenheiro e marechal de campo Beaurepaire Rohan, de 1843, marca importante mudança. Ao alegar que muitos dos problemas decorriam da inexistência de um arranjo global, sugeriu o Plano Colossal com aplicação de regras geométricas ao desenho da cidade e de normas de edificação e de parcelamento, assim como a arborização dos espaços livres para aeração e prazer. Considerando a poluição da Baía de Guanabara "uma indecência", propôs a derrubada do morro do Castelo, a drenagem dos charcos, a pavimentação de ruas, o deslocamento de matadouros, cemitérios e hospitais e a implantação do abastecimento de água, da coleta de lixo e do esgotamento sanitário. Para facilitar a circulação, recomendou a demolição de mais de 5.000 prédios (que 
corresponderiam a $40 \%$ dos existentes) a partir daqueles de menor valor, e a ampliação do número de quadras com a abertura ou prolongamento de mais de cinquenta ruas e praças na direção oeste da cidade. A largura das ruas teria 17,6 metros, os quarteirões mediriam 66 metros e a testada dos lotes padrão com 13,2 metros. Para o financiamento deste plano urbano organizar-se-ia uma sociedade por ações com participação dos proprietários das casas e de empresas privadas além dos recursos advindos de novos impostos. Rohan, ao considerar o poder público "acima dos interesses particulares e visando o bem da sociedade" (RABHA, 2008, p. 17), recomendava-Ihe conhecer as demandas e as condições sociais. E, sendo um entusiasta do progresso e do espraiamento, indicava a construção de estradas de ferro para "harmonizar" o território. São inegáveis algumas semelhanças com as proposições pós-fourieristas de Perreymond.

Propostas de posturas foram apresentadas pelos vereadores Gonçalves Fontes e Manuel de Araujo Porto Alegre, nas quais nenhuma casa poderia ser edificada ou reformada sem estar de acordo com o "prospecto estabelecido pela Câmara Municipal" sob pena de multa. E enquanto

\footnotetext{
[...] não existirem os planos que para esse fim deverão estar patentes no paço da llma. Câmara Municipal, nenhuma licença de construção ou reconstrução será concedida sem que seja o prospecto submetido à Câmara e por ela aprovado [...]. (DIÁRIO DO RIO DE JANEIRO, 25 jul. 1853, p.1, grifo nosso).
}

Na mesma sessão da Câmara, Porto Alegre, lamentando que a cidade ainda não tivesse "um plano que determine o seu futuro!", dizia ser necessário começar "a planta da cidade futura e sobre ela criar essa nova cidade que deverá em poucos anos tomar o caráter da capital de um império". E ainda sugeriu que não se concedessem parcelas de terras dentro ou fora da cidade ou se abrissem novas ruas.

Um personagem que deve ser citado é o barão de Mauá, comissionado em 1857 para a obra de abertura de um canal no Mangue da Cidade Nova, na perspectiva dos "melhoramentos", soma de higiene com embelezamento. Este empreendimento, que contou com quatrocentos trabalhadores, localizava-se em uma região com sérios problemas de saneamento. Ali também estava sendo erguida sua companhia de gás para iluminação pública. Além de disponibilizar aos empregados dormitórios coletivos, biblioteca, cozinha, botica, tanques para lavar roupa e jardins, declarava-se abolicionista e introduziu os caminhos de ferro e a indústria no país, razões para tornar-se representante do "sansimonismo industrial brasileiro" de acordo com Abramson (1999).

A marca do que então se instaura como pensamento "urbanístico" no Rio de Janeiro vincula-se ao plano geral, cuja base era a higiene pública, institucionalizando a medicina social, organizada como poder político, e que se tornou uma ideologia do Estado (CHALHOUB, 2003). E não por coincidência aportou como funcionário do império, em 1858, o botânico francês Auguste François Marie Glaziou, para realizar projetos paisagísticos em espaços públicos seguindo o modelo haussmanniano de Paris. Da década de 1860 datam a instalação de redes de esgotos e de águas pluviais na área central e o Relatório da Junta Central de Higiene Pública. Este Relatório trazia cláusulas relativas às fachadas, às praças e à uniformização da altura dos edifícios, que variava de acordo com a localização, consideradas por Villaça (1999) como um esboço de zoneamento. Neste sentido, desígnios para remodelação de bairros, alargamento de ruas, arborização, redes de água e esgotos e limpeza pública foram aventados no intuito de transformar o Rio de Janeiro em modelo com a definição de "diretrizes a serem seguidas pelos poderes locais e central" (RABHA, 2008, p. 38). E com o ideário socialista romântico já desaparecendo dos projetos de intervenção, consolidou-se a dimensão técnica e normativa com aparente caráter universal e despolitizado, base dos planos que se seguirão.

Nos anos setenta do Oitocentos o Ministério do Império teria reafirmado como questões urgentes a melhoria das condições higiênicas e de circulação, recrudescendo o debate relativo à "habitação proletária", tema que deu origem a propostas de legislação e de constituição de empresas de construção de moradias populares. Foram também elaborados dois Relatórios da Comissão de Melhoramentos da Cidade (1875 e 1876), chamados de "Plano dos Engenheiros", e os Relatórios da Junta de Higiene, dos quais será destacado o de 1878, o "Plano dos Médicos".

O primeiro relatório da Comissão de Melhoramentos definiu como focos de atuação a zona periférica ao centro e o conjunto de normas para a construção de casas particulares, sobretudo quanto à ventilação. Tal perspectiva relacionava-se à explicação das causas das epidemias associadas aos cortiços, inclusive concentrados em uma localidade estratégica para a expansão urbana, a Cidade Nova. ${ }^{4}$ Esta região 
foi definida como prioritária para as obras de saneamento, de alargamento e abertura de ruas e praças, de dessecamento dos pântanos e de escoamento das águas pluviais a serem executadas pelo setor privado em regime de concessão. A "Cidade Velha" foi a área indicada pelo segundo Relatório, para a qual se cogitavam o arrasamento dos morros do Castelo, Santo Antônio e do Senado, a retificação das principais ruas com a derrubada de prédios de pequeno valor e a abertura de dois grandes eixos que facilitariam a circulação em direção aos arredores. Neste sentido, foram duas as regiões da cidade privilegiadas, reintroduzindo-se a atuação pontual.

No "Plano da Junta de Higiene" constavam quarenta medidas para acabar com os surtos de febre amarela e mais trinta para tornar a cidade mais salubre. Sobressai, no entanto, aquela que a atuação pública deveria incluir entre suas prerrogativas a promulgação de normas para melhoria das "habitações das classes pobres" e a proibição de edificação de novos cortiços (SILVA, 2012), significando que o binômio cortiço-doença havia se tornado o elemento fundamental de intervenção na cidade.

\section{Palavras finais}

Desta narrativa resultam indícios. Inicialmente, o ideário socialista romântico nas primeiras décadas do século XIX pregava a conservação do que havia de bom aliada à melhoria do insuficiente em uma justaposição de princípios éticos cristãos com a técnica: o "novo cristianismo" (ou a "religião da ciência") inspirava mudanças no sentido de uma nova sociedade onde as classes sociais conviveriam em harmonia. A vinda ao país de imigrantes notadamente franceses - profissionais liberais, militantes e trabalhadores assim como os clamores de nossos filantropos, idealistas, associações civis, imprensa e da igreja aceleraram a circulação de conceitos e de modelos adaptados ao regime político em vigor. Estes modelos podem ser lidos como formulações de um socialismo "generoso" e "escassamente subversivo" se comparado ao socialismo revolucionário da segunda metade do século.

Em segundo lugar, os socialistas pragmáticos e os reformadores da primeira metade do século XIX prescreviam a "higiene para o povo" e o progresso geral, mas suas mais importantes proposições estão presentes nas concepções de totalidade territorial (a "metrópole" no contexto

4. Esta moradia dos trabalhadores pobres (ex-escravos e estrangeiros brancos) abrigava, em 1870, 21.929 pessoas naquela área. regional e nacional; o sistema de tensões entre núcleos) e de plano de conjunto para a cidade. Se para o século XIX devemos ser cautelosos ao utilizar expressões como urbanismo e planejamento urbano e regional sob risco de anacronismo, é inegável que suas raízes já se encontravam fincadas.

Finalmente, quanto aos projetos para o Rio de Janeiro, ainda que o plano Beaurepaire Rohan demonstrasse preocupações com as condições sociais, tanto ele como os planos posteriores vão assumir um caráter técnico e normativo seguindo as propostas geometrizantes e repressivas haussmannianas. Serão soluções para o problema da habitação popular e de pontuais melhoramentos, através de uma política urbanizadora como remédio aplicado a posteriori, para preparar a modernidade industrial com a sua impossível estabilidade política do último quartel do século.

\section{Referências}

ABRAMSON, P. L. Las utopías sociales en América Latina en el siglo XIX. Mexico: Fondo de Cultura Económica, 1999.

ABREU E LIMA, J. I. O socialismo. Rio de Janeiro: Paz e Terra, 2001.

CHALHOUB, S. Machado de Assis: o historiador. São Paulo: Cia. das Letras, 2003.

FRIDMAN, F. Uma cidade nova no Rio de Janeiro. Revista Acervo, v. 1, p. 139-152, 2009.

HOBSBAWM, E. A era das revoluções - 17891848. São Paulo: Paz e Terra, 1994.

LOWY, M. Romantismo e messianismo. São Paulo: Perspectiva, 2008.

MENDONÇA, V. Três datas históricas do urbanismo carioca. Revista da Directoria de Engenharia, v. 5, p. 319-325, 1936.

MATTOS, S. R. Para formar os brasileiros: o Compêndio da História do Brasil de Abreu e Lima e a expansão para dentro do império do Brasil. 2007. Tese (Doutoramento) - Programa de Pós-Graduação em História, USP, 2007.

MORET, F. Penser la ville en fouriériste: les projets pour Paris de Perreymond. In: BOWIE, K. (Org.). La modernité avant Haussmann: formes de l'espace urbain à Paris 1801-1853. Paris: Editions Recherches, 2001. 
RABHA, N. C. E. (Coord.). Planos urbanos: Rio de Janeiro, o século XIX. Rio de Janeiro: Instituto Pereira Passos, 2008.

RODRIGUES, E. Pequena história da imprensa social no Brasil. Disponível em: <www.portalgens.com.br/comcom/textos.htm>. Acesso em: 11 jan. 2012.

SILVA, L. P. Memórias do urbanismo na cidade do Rio de Janeiro - 1778-1878: Estado, administração e práticas de poder. Rio de Janeiro: Epapers, 2012.

SOBRINHO, B. L. Prefácio. In: ABREU E LIMA, J. I. O socialismo. Rio de Janeiro: Paz e Terra, 2001.

VILLAÇA, F. Uma contribuição para a história do planejamento urbano no Brasil. In: DÉAK, C.; SCHIFFER, S. (Org.). O processo de urbanização no Brasil. São Paulo: Fupam/Edusp, 1999. 
